\title{
Peningkatan Kreativitas Belajar dalam Pembelajaran PKN Melalui Model Discovery Learning pada Siswa Kelas XI SMA UNIMUDA Sorong
}

\author{
Aldilla Yulia W.S. M.H. ${ }^{1}$ Ihsan, M.Pd. ${ }^{2}$ Sri Rizki Handayani, M.Pd. ${ }^{3}$ \\ Program Studi Pendidikan Pancasila dan Kewarganegaraan \\ Universitas Pendidikan Muhammadiyah (UNIMUDA) Sorong \\ Aldilla.wiellys@gmail.com, sririzkihandayani.srh@gmail.com
}

\begin{abstract}
Abstrak: Tujuan penelitian ini adalah untuk meningkatkan kreativitas belajar dalam pembelajaran PKn melalui model pembelajaran penemuan (discovery learning) pada siswa kelas XI SMA Muhammadiyah Lab School Arar. Jenis penelitian ini adalah Penelitian Tindakan Kelas yang dilaksanakan dalam dua siklus yang terdiri dari perencanaan, pelaksanaan, observasi, dan refleksi. Subjek penelitian ini adalah siswa kelas XI SMA Muhammadiyah Lab School Arar yang berjumlah 16 orang dan objek penelitiannya adalah kreativitas belajar dalam pembelajaran PKn melalui model pembelajaran penemuan (discovery learning). Teknik pengumpulan data yang digunakan adalah tes, observasi, angket, dan dokumentasi. Teknik analisis data yang digunakan terdiri dari empat komponen, yaitu pengumpulan data, reduksi data, sajian data, dan penarikan kesimpulan atau verifikasi. Indikator kreativitas belajar siswa, yaitu: 1) memiliki rasa ingin tahu yang besar, 2) memiliki kemandirian yang tinggi, 3) memiliki kesenangan dalam mengerjakan tugas yang sulit, 4) memiliki inisiatif, dan 5) berani menyatakan pendapat dan keyakinannya. Kriteria keberhasilan penelitian untuk kreativitas belajar adalah telah mencapai nilai KKM 75 dan ketuntasan kelas sebesar 85\%. Hasil penelitian menunjukkan bahwa terjadi peningkatan kreativitas belajar siswa dalam pembelajaran PKn melalui model pembelajaran penemuan (discovery learning). Peningkatan tersebut dapat dilihat pada tahap pra siklus, siklus I, dan siklus II. Pada tahap pra siklus diketahui kreativitas belajar siswa rendah dengan persentase $37,5 \%$. Pada siklus I kreativitas belajar siswa meningkat dengan persentase $62,5 \%$. Pada siklus II kreativitas belajar siswa mengalami peningkatan yang sangat baik dengan persentase $87,5 \%$.
\end{abstract}

Kata Kunci: Discovery Learning, Kreativitas Belajar PKn.

Abstract: The purpose of this study is to enhance creativity in teaching civics learning through discovery learning model (discovery learning) students of class XI SMA Muhammadiyah Lab School Arar. This type of research is the Classroom Action Research conducted in two cycles of planning, execution, observation, and reflection. The subjects were students in grade XI SMA Muhammadiyah Lab School Arar totaling 16 students, and the object of research is the study of creativity in learning civics through discovery learning model (discovery learning). Data collection techniques used were tests, observations, questionnaires, and documentation. Data analysis technique used consists of four components, namely data collection, data reduction, data presentation, and conclusion or verification. Indikators creativity of student learning, namely: 1) have a great curiosity, 2) have a high independence, 3) have the pleasure of doing a difficult task, 4) have the initiative, and 5) dare to express opinions and beliefs. The success criteria for the study of learning is creativity has reached the KKM 75 and the thorougless of the class by $85 \%$. The results showed that an increase in creativity in teaching civics student learning through discovery learning model (discovery learning). Such improvements can be seen in the pre-stage of the cycle, the first cycle, and the second cycle. In the pre-stage learning cycle know low student creativity with the percentage were $37,5 \%$. In the first cycle of creativity of student learning increases with the 
percentage to be $62,5 \%$. In the second cycle of creativity of student learning had increase very well with a percentage were $87,5 \%$.

Keywords: Discovery Learning, Creativity Learning Civics.

\section{Pendahuluan}

Undang-Undang Republik Indonesia Nomor 20 Tahun 2003 tentang Sistem Pendidikan Nasional menyebutkan bahwa pendidikan adalah usaha sadar dan terencana untuk mewujudkan suasana belajar dan proses pembelajaran agar peserta didik secara aktif mengembangkan potensi dirinya untuk memiliki kekuatan spiritual keagamaan, pengendalian diri, kepribadian, kecerdasan, akhlak mulia, serta keterampilan yang diperlukan dirinya, masyarakat, bangsa, dan negara. Pendidikan nasional adalah pendidikan yang berdasarkan Pancasila dan UUD RI Tahun 1945 yang berakar pada nilai-nilai agama, kebudayaan nasional Indonesia dan tanggap terhadap tuntutan perubahan zaman. Sistem pendidikan nasional adalah keseluruhan komponen pendidikan yang saling terkait secara terpadu untuk mencapai tujuan pendidikan nasional.

Pendidikan Nasional yang berdasarkan Pancasila dan UUD 1945 berfungsi mengembangkan kemampuan dan membentuk watak serta peradaban bangsa yang bermartabat dalam rangka mencerdaskan kehidupan bangsa, bertujuan untuk mengembangkan potensi peserta didik agar menjadi manusia yang beriman dan bertakwa kepada Tuhan Yang Maha Esa, berakhlak mulia, sehat, berilmu, cakap, kreatif, mandiri, dan menjadi warga negara yang demokratis serta bertanggung jawab. Untuk mewujudkan fungsi tersebut pemerintah menyelenggarakan suatu Sistem Pendidikan Nasional.

Implementasi Undang-Undang Republik Indonesia Nomor 20 Tahun 2003 tentang Sistem Pendidikan Nasional tersebut dijabarkan dalam sejumlah peraturan, antara lain Peraturan Pemerintah Republik Indonesia Nomor 19 Tahun 2005 tentang Standar Nasional Pendidikan yang di dalamnya memuat 8 (delapan) standar, yaitu Standar Isi, Standar Proses, Standar Kompetensi Lulusan, Standar Pendidik dan Tenaga Kependidikan, Standar Sarana dan Prasarana, Standar Pengelolaan, Standar Pembiayaan, dan Standar Penilaian Pendidikan.

Sekolah sebagai lembaga kedua setelah keluarga dalam membentuk karakteristik siswa dan pengembangan potensi siswa merupakan kelanjutan pengenalan pelajaran PKn yang pertama. Untuk itu, sudah menjadi tugas sekolah untuk mengajarkan mata pelajaran PKn kepada peserta didik dengan tujuan mengembangkan karakteristik dan potensi yang dimiliki peserta didik.

Pendidikan Pancasila dan Kewarganegaraan merupakan mata pelajaran yang memfokuskan pada pembentukan warga negara yang memahami dan mampu melaksanakan hak-hak dan kewajibannya untuk menjadi warga negara Indonesia yang cerdas, terampil, dan berkarakter yang diamanatkan oleh Pancasila dan UUD 1945.

Pencapaian tujuan mata pelajaran PKn menghendaki bukan saja agar peserta didik mampu berpikir secara kritis, rasional, dan kreatif dalam menanggapi isu kewarganegaraan, tetapi juga dalam proses pembelajaran peserta didik dituntut untuk dapat berpartisipasi secara aktif dan bertanggung jawab, dan bertindak secara cerdas dalam kegiatan bermasyarakat, berbangsa, dan bernegara, serta antikorupsi, berkembang secara positif dan demokratis untuk membentuk diri berdasarkan karakter-karakter masyarakat Indonesia agar dapat hidup 
bersama dengan bangsa-bangsa lainnya, berinteraksi dengan bangsa-bangsa lain dalam percaturan dunia secara langsung atau tidak langsung dengan memanfaatkan teknologi informasi dan komunikasi. Untuk dapat mencapai tujuan tersebut maka harus dilaksanakan pendekatan pembelajaran yang mengedepankan pendekatan proses.

Berdasarkan tujuan dari mata pelajaran PKn tersebut, salah satunya peserta didik harus berpikir kreatif dalam menanggapi isu kewarganegaraan. Untuk itu, sudah menjadi tugas seorang guru untuk menciptakan pembelajaran yang dapat merangsang peserta didik untuk berpikir kreatif. Apalagi kenyataan di lapangan menunjukkan bahwa guru PKn dalam menyampaikan pelajaran selalu mengutamakan aspek pengetahuan atau kognitif. Selain itu, masih banyak guru dalam memberikan pelajaran menggunakan metode yang konvensional atau ceramah sampai jam mata pelajaran selesai.

Dengan metode ceramah dan aspek kognitif yang diutamakan, pelajaran berjalan satu arah. Guru yang aktif dan peserta didik atau siswa yang pasif, materi pelajaran aspek kognitifnya bersifat verbal. Hal itulah yang menyebabkan peserta didik bosan dan tidak dapat berpikir kreatif dalam menanggapi isu kewarganegaraan sehingga tidak tercipta suasana belajar yang menyenangkan dan hidup dalam kelas serta menyukai pelajaran PKn.

Guru dalam mengajarkan PKn dapat mencoba menggunakan Model Pembelajaran Discovery Learning untuk membangkitkan kreativitas dan keingintahuan peserta didik. Discovery Learning adalah teori belajar yang menempatkan peserta didik sebagai pembelajar aktif dalam membangun pengetahuan yang diharapkan. Proses pembelajaran dapat terjadi dengan baik apabila metode dan teknik pembelajaran melibatkan peserta didik. Keterlibatan diri (ego peserta didik) adalah kunci keberhasilan dalam pembelajaran PKn.

Untuk itu pendidik hendaknya mampu membantu peserta didik dalam :

a. mendefinisikan kebutuhan belajarnya,

b. merumuskan tujuan belajar,

c. ikut serta memikul tanggung jawab dalam perencanaan dan penyusunan pengalaman belajar, dan

d. berpartisipasi dalam mengevaluasi proses dan hasil kegiatan belajar. Dengan demikian, setiap pendidik harus melibatkan peserta didik seoptimal mungkin dalam kegiatan pembelajaran.

Dari permasalahan yang telah dikemukakan di atas, maka penulis ingin melakukan penelitian tentang bagaimana meningkatkan kreativitas belajar dalam pembelajaran PKn melalui model pembelajaran discovery learning pada siswa kelas XI SMA Muhammadiyah Lab School Arar.

\section{Metode Penelitian}

Penelitian ini adalah penelitian tindakan kelas (PTK), hal ini dipilah atas dasar masalah dan tujuan penelitan yang memerlukan berbagai informasi dan tindak lanjut yang terjadi dilapangan. Penelitian dilakukan untuk memecahkan masalah pembelajaran di kelas. Penelitian ini juga termasuk penelitian deskriptif, sebab menggambarkan bagaimana suatu teknik pembelajaran diterapkan dan bagaimana hasil yang di inginkan dapat tercapai. Melalui penggunaan model pembelajaran penemuan (discovery learning) diharapkan dapat meningkatkan kreativitas belajar PKn di kelas XI MA Muhammadiyah Lab School Arar. 
Rancangan penelitian tindakan kelas ini dilakukan dalam dua siklus dimana dalam masing-masing siklus tersebut terdiri atas beberapa tahap yaitu perencanaan, pelaksanaan, observasi, dan refleksi. Pengumpulan data dalam penelitan ini menggunakan angket, observasi, dan tes hasil belajar. Data kuantitatif dianalisis dengan statistik deskriptif, untuk mendeskripsikan hasil tindakan pada tiap siklus dan antar siklus. Data kualitatif dianalisis dengan menggunakan model interaktif dan trianggulasi yang diperoleh dari hasil observasi guru dan siswa, catatan lapangan, dan angket.

\section{Hasil dan Pembahasan}

Penelitian dilakukan pada sikus I terdiri dari tahap perencanaan, pelaksanaan, observasi dan refleksi. keempat tahap tersebut telah dilakukan dalam tiap kali pertemuan. Siklus I dilaksanakan dalam dua kali pertemuan yaitu pertemuan pertama pemberian materi dan pertemuan dua tes akhir siklus. Hasil evaluasi siklus I yang diperoleh dari tes hasil belajar siklus satu tersebut adalah nilai rata-rata 69,8 dan ketuntasan klasikal 62,5\%. Ini menunjukkan bahwa ketuntasan kreativitas belajar siswa masih rendah. Oleh karena itu perlu adanya perbaikan yang dilakukan pada siklus II.

Tabel 1. Hasil Kreativitas Belajar Siswa Siklus I

\begin{tabular}{clc}
\hline No. & \multicolumn{1}{c}{ Nama Siswa } & Tes Siklus I \\
\hline 1. & Agung Rejo Purnomo & 46,5 \\
2. & Fitriyani. D. Jare & 80 \\
3. & Gawalia Bangapadang & 76,5 \\
4. & Hasbulah Kumkelo & 75 \\
5. & Marawia Gurium & 76,5 \\
$\mathbf{6 .}$ & Muhammad Ali Topan & 76,5 \\
7. & Muhammad Putra Ramadhan & 62 \\
8. & Nurul Astin & 79,5 \\
9. & Sabil Imbimbong & 60,5 \\
10. & Sahrul Rahman & 47,75 \\
11. & Sainah Tanoi & 81,5 \\
12. & Siti Iriyanti & 61,25 \\
13. & Siti Syarah Yeblo & 76,5 \\
14. & Taufiq & 61,25 \\
15. & Vivi Fitriani Muhsin & 78,75 \\
16. & Zulkifly & 75,75 \\
& Jumlah & $\mathbf{1 1 1 5 , 7 5}$ \\
& Nilai Rata-Rata & $\mathbf{6 9 , 8}$ \\
\hline & Persentase Ketuntasan & $\mathbf{6 2 , 5 \%}$ \\
\hline
\end{tabular}

Pelaksanaan penelitian siklus II dilakukan hampir sama dengan siklus I yang terdiri dari tahap perencanaan, pelaksanaan, observasi, refleksi. Pelaksanaan siklus II dilkukan lebih maksimal dibandingkan dengan siklus I untuk melakukan perbaikan dari pelaksanaan siklus I. Dalam siklus II ini dilakukan dua kali pertemuan yaitu pertemuan pertama pemberian materi dan pertemuan kedua tes akhir siklus. Berdasarkan hasil refleksi dan perbaikan dari siklus I maka di siklus II ini nilai rata-rata kreativitas belajar siswa 76,25 dan ketuntasan klasikal mencapai $87,5 \%$. Ini menunjukkan penelitian dapat dikatakan berhasil karena 
hasil yang diperoleh pada silkus II telah mencapai ketuntasan lebih dari $85 \%$ dan nilai rata-rata siswa berada di atas KKM 75.

Tabel 2. Hasil Kreativitas Belajar Siswa Siklus II

\begin{tabular}{|c|c|c|}
\hline No. & Nama Siswa & Tes Siklus II \\
\hline 1. & Agung Rejo Purnomo & 61,75 \\
\hline & Fitriyani. D. Jare & 82 \\
\hline & Gawalia Bangapadang & 79,5 \\
\hline & Hasbulah Kumkelo & 77 \\
\hline 5. & Marawia Gurium & 79,5 \\
\hline & Muhammad Ali Topan & 77 \\
\hline & Muhammad Putra Ramadhan & 75 \\
\hline & Nurul Astin & 79,5 \\
\hline & Sabil Imbimbong & 75 \\
\hline 10. & Sahrul Rahman & 66,25 \\
\hline 11. & Sainah Tanoi & 83,25 \\
\hline 12. & Siti Iriyanti & 75,5 \\
\hline 13. & Siti Syarah Yeblo & 77 \\
\hline 14. & Taufiq & 75 \\
\hline 15. & Vivi Fitriani Muhsin & 79,25 \\
\hline \multirow[t]{4}{*}{16.} & Zulkifly & 77,5 \\
\hline & Jumlah & 1220 \\
\hline & Nilai Rata-Rata & 76,25 \\
\hline & Persentase Tuntas & $87,5 \%$ \\
\hline \multicolumn{3}{|c|}{$\begin{array}{l}\text { pelajaran PKn siswa kelas XI MA Muhammadiyah Lab School Arar, dapat } \\
\text { meningkat. Model pembelajaran discovery learning merupakan nama lain dari } \\
\text { pembelajaran penemuan. Sesuai dengan namanya, model ini mengarahkan siswa } \\
\text { untuk dapat menemukan sesuatu melalui proses pembelajaran yang dilakoninya. } \\
\text { Siswa diraih untuk terbiasa menjadi seorang saintis (ilmuwan). Mereka tidak } \\
\text { hanya sebagai konsumen, tetapi diharapkan pula bisa berperan aktif, bahkan } \\
\text { sebagai pelaku dari pencipta ilmu pengetahuan. Pembelajaran penemuan model } \\
\text { ini merupakan bagian dari kerangka pendekatan saintifik. Siswa tidak hanya } \\
\text { disodori oleh sejumlah teori (pendekatan deduktif), tetapi mereka pun berhadapan } \\
\text { dengan sejumlah fakta (pendekatan induktif). Dari teori dan fakta itulah, mereka } \\
\text { diharapkan dapat merumuskan sejumlah penemuan. Bentuk penemuan yang } \\
\text { dimaksud tidak selalu identik dengan suatu teori ataupun benda sebagaimana yang } \\
\text { biasa dilakukan kalangan ilmuwan dan professional dalam pengertian yang } \\
\text { sebenarnya. Penemuan yang dimaksud berarti pula sesuatu yang sederhana, } \\
\text { namun memiliki makna dengan kehidupan para siswa itu sendiri. Penemuan itu } \\
\text { tetap berkerangka pada kompetensi-kompetensi dasar (KD) yang ada pada } \\
\text { kurikulum. }\end{array}$} \\
\hline \multicolumn{3}{|c|}{$\begin{array}{l}\text { Berdasarkan temuan dan hasil analisis data hasil belajar siswa siklus I nilai } \\
\text { rata-rata siswa sebesar } 69,8 \text { dan ketuntasan klasikal } 62,5 \% \text { dan jumlah siswa yang } \\
\text { tuntas hanya sebanyak } 10 \text { orang siswa. Penelitian dikatakan berhasil jika } \\
\text { ketuntasan individual siswa minimal memperoleh nilai } 75 \text { dan ketuntasan klasikal } \\
\text { sama dengan } 85 \% \text {. Jadi kriteria keberhasilan penelitian secara klasikal dan secara } \\
\text { individual belum tercapai karena masih ada } 6 \text { orang siswa yang belum tuntas }\end{array}$} \\
\hline
\end{tabular}


secara individual. Hal ini disebabkan dalam proses pembelajaran masih ada beberapa kendala yang terjadi selama tindakan siklus I seperti yang dipaparkan pada refleksi siklus I.

Melalui perbaikan tindakan pada siklus I yaitu lebih mengoptimalkan cara belajar siswa dengan lebih aktif untuk menemukan dan mencari sendiri dengan memberikan masalah-masalah untuk ia pecahkan maka pada siklus II diperoleh nilai rata-rata siswa sebesar 76,25 dan ketuntasan klasikal 87,5\% dan jumlah siswa yang tuntas sebanyak 14 orang. Hal ini berarti menunjukkan secara klasikal keseluruhan ketuntasan individual dan klasikal dalam siklus II sudah terpenuhi.

Berdasarkan hasil temuan saat penelitian dengan menggunakan model yang dipaparkan di atas bahwa dengan penggunaan pembelajaran PKn dengan model discovery learning dapat meningkatkan kreativitas belajar siswa. Akan tetapi terlepas dari keberhasilan tesebut tentunya terdapat kendala yang menghambat, namun di dalam mensukseskan pelaksanaan pembelajaran ini memerlukan upaya yang dilakukan oleh guru. Guru berupaya menemukan solusi guna meminimalisir kendala yang dihadapi saat penerapan model pembelajaran tersebut sehingga pembelajaran bisa mendapatkan hasil yang maksimal.

\section{Kesimpulan dan Saran}

Kesimpulan dari hasil penelitian dan pembahasan adalah pembelajaran PKn melalui model pembelajaran discovery learning yang telah dilaksanakan di kelas XI SMA Muhammadiyah Lab School Arar tahun pelajaran 2019/2020 dapat meningkatkan kreativitas belajar siswa pada pokok bahasan Sistem Hukum dan Peradilan Internasional.

Hal tersebut dapat dilihat dalam pembahasan hasil penelitian, yaitu sebelum perbaikan atau pretest persentase ketuntasan adalah 37,5\%, pada siklus I presentase ketuntasan siswa meningkat menjadi $62,5 \%$, dan pada siklus II hasil persentase ketuntasan meningkat menjadi $87,5 \%$.

Berdasarkan pengamatan peneliti selama melaksanakan penelitian tindakan kelas pada kelas XI MA Muhammadiyah Lab School Arar, peneliti memberikan saran sebagai berikut:

1. Model pembelajaran penemuan (discovery learning) ini dapat dilaksanakan oleh guru karena dengan pembelajaran tersebut dapat membangkitkan kreativitas belajar dan keingintahuan siswa dalam pembelajaran PKn.

2. Dalam pembelajaran, guru dituntut untuk selalu kreatif dalam proses kegiatan belajar mengajar sehingga dapat memotivasi siswa untuk lebih semangat dalam mengikuti pembelajaran.

3. Dalam kegiatan belajar mengajar perlu dimasukkan aspek kreativitas selain hasil belajar karena dengan kreativitas, siswa dapat menghadapi dan menyelesaikan permasalahan didunia nyata secara lebih baik.

\section{Daftar Pustaka}

Anonim. 2014. Pembelajaran Pendidikan Kewarganegaraan Melalui Pendekatan Saintifik. Jakarta: Direktorat Pembinaan SMA Direktorat Jenderal Pendidikan Menengah Kementerian Pendidikan dan Kebudayaan.

Anonim, "Undang-Undang No. 20 Tahun 2003 Tentang Sistem Pendidikan Nasional", diakses dari http://kemenag.go.id/file/dokumen/UU2003.pdf, pada tanggal 22 Desember 2015. 
Aunurrahman. 2013. Belajar dan Pembelajaran. Bandung: Alfabeta.

Dita Wahyu Tri Utaminingsih, "Upaya Peningkatan Prestasi Belajar PKn Melalui Metode Pembelajaran Think-Pair-Share (TPS) Bagi Siswa Kelas VII C SMPN 3 Prambanan Tahun Ajaran 2009/2010", hlm. 2, diakses dari http://digilib.uns.ac.id/dokumen/download/pdf/..., pada tanggal 22 Desember 2015.

Hawadi, Reni Akbar, dkk. 2001. Kreativitas. Jakarta: PT. Grasindo.

Info Publik, 2014, "Pengertian Dan Indikator Kreativitas Belajar", diakses dari http://publik22.blogspot.com>Home>Belajar dan Pembelajaran, pada tanggal 5 Januari 2016.

Kosasih, E. 2014. Strategi Belajar dan Pembelajaran Implementasi Kurikulum 2013. Bandung: Yrama Widya.

Munandar, Utami. 2002. Membangun Bakat dan Kreativitas Anak Sekolah. Jakarta: Gramedia.

1992. Mengembangkan Bakat dan Kreativitas Anak Sekolah.

Jakarta: Gramedia.

Pendidikan Kewarganegaraan, "Hakekat dan Tujuan Pembelajaran PKn", diakses dari http://pknkita.blogspot.com/2011/05/hakekat dan tujuan pembelajaran PKn, pada tanggal 20 Juni 2015.

Pendidikan Kewarganegaraan, 2015, "Kreativitas Belajar Siswa", diakses dari http://ainamulyana.blogspot.com>Home>Berita $>$ Pembelajaran, pada tanggal 23 Desember 2015.

Prodi PGSD, "Pengertian, Tujuan Dan Ruang Lingkup Pembelajaran PKn", diakses dari http://dodirullyandapgsd.blogspot.com>Home>PGSD, pada tanggal 22 Juni 2015.

P3G-UNM, “[PDF] Discovery Learning”, diakses dari http://p3.unm.ac.id/index.php/download/ca... , pada tanggal 23 Desember 2015.

Semiawan, Conny, dkk. 1987. Pendekatan Keterampilan Proses : Bagaimana Mengaktifkan Siswa Dalam Belajar?. Jakarta: Gramedia.

Syah. 2004. Psikologi Pendidikan dengan Pendekatan Baru. Bandung: PT. Remaja Rosdakarya.

Tim Dosen BPF, "Model-Model Pembelajaran", diakses dari http://file.upi.edu/ ../Learning_Models.ppsx, pada tanggal 23 Desember 2015.

Usman. 1993. Upaya Optimalisasi Kegiatan Belajar Mengajar. Jakarta: PT. Remaja Rosdakarya.

Widyasari, Choiriyah. Kreativitas dan Keterbakatan. Surakarta: Qinant. 